\title{
Assessment of Psychological Health Status in Geriatric Patients with Obstructive Sleep Apnea
}

\author{
Hanem Reda Bassuni Anan1, Marwa Omar Mohamed2 and Soad Hassan Abd Elhameed3
}

1, 3 Department of Gerontological Nursing, Faculty of Nursing, Mansoura University, Egypt 2 Department of Chest Medicine, Faculty of Medicine, Mansoura University, Egypt

\begin{abstract}
Background: obstructive sleep apnea is a chronic and highly prevalent disorder that is considered to be a true public health problem. The sleep disturbance pattern related to obstructive sleep apnea negatively influences the stress system and hence increases the vulnerability of obstructive sleep apnea patients to anxiety and depression. Aim: Assess the psychological health status in geriatric patients with obstructive sleep apnea. Method: Descriptive research design was used in this study. This study was conducted in the outpatient clinic of the Chest Medicine Department at Main Mansoura University Hospital. A purposive sample of 100 geriatric patients with obstructive sleep apnea was enrolled in the study. Data was collected using 3 tools; Geriatric Patient's Demographic characteristics and Clinical Data Sheet, hospital anxiety and depression scale, and Epworth Sleepiness Scale. Results: The mean score of anxiety was $12.03 \pm 3.76$ and depression was $9.16 \pm 2.86$ with $80.0 \%$ of the studied elders had anxiety and $64.0 \%$ had depression. In addition, a strong positive correlation was found between obstructive sleep apnea severity and anxiety and depression $(\mathrm{P}=0.001 *)$. Conclusion: Anxiety and depression were common psychological problems in geriatric patients with obstructive sleep apnea. Recommendation: Implementation of an intervention program for nursing staff about problems faced in caring for patients with obstructive sleep apnea to help them to provide optimal care and early screening of psychological problems in order to prevent further deterioration.
\end{abstract}

Keywords: Psychological health Status, Obstructive sleep apnea, Geriatric patients. 


\section{Introduction}

The aging population of the world is rapidly increasing. The proportion of older adults $\geq 60$ years old will double from $12 \%$ to $22 \%$ Between 2015 and 2050. The increase in the aged population will bring with it a huge burden of sleep-related health problems ${ }^{1}$. Particularly, patient with obstructive sleep apnea (OSA) is the most common form of sleep-related breathing disorder. OSA Is characterized by the upper airway's complete or partial occlusion during sleep. The results restrict airflow and can result in intermittent hypoxemia and fragmentation of sleep $^{2}$. Mental health is a significant factor in the health status of older adults and it has significant importance in accomplishing successful aging and having a satisfactory quality of life among older adults in different societies ${ }^{3}$.

The recurrent sleep disturbance caused by untreated OSA has a significant sequel for daytime functioning, consisting of profound daytime somnolence and deterioration in emotional well-being. Psychological symptoms such as depression and anxiety are one of the most common comorbidities in obstructive sleep apnea patients that may affect prognosis, quality of life and adherence to treatments. ${ }^{4}$. Hence, the psychological health status of geriatric patients with obstructive sleep apnea should be assessed.

\section{Research questions:}

Q1: What is the level of psychological health status in geriatric patients with obstructive sleep apnea?

Q2: What is a relationship between OSA severity and psychological health status in geriatric patients with obstructive sleep apnea?
Method

Research design: Descriptive design was utilize to conduct this study.

Study setting :

This study was carried out in the outpatient clinic of the Chest Medicine Department at Main Mansoura University Hospital.

Subjects of the study:

The study included a purposive sample of 100 elderly patients diagnosed with OSA. Elderly patients were selected according to certain characteristics; patient aged 60 years and more, a patient diagnosed with obstructive sleep apnea, able to interact, ready to participate in the study, and available at the selected setting during the period of data collection. Exclusion criteria included the patients suffering from; neurological disorders, respiratory disorders other than OSA, with a history of traumatic brain injury, taking medication that may affect cerebral functioning, and patients undergoing treatment for OSA. The sample size was estimated through clincal.com sample size calculator software, at $5 \% \infty$ error $(95.0 \%$ significance) and $10.0 \% \beta$ error $(90.0 \%$ power of the study), the average minimental state examination among elderly not suffering from OSA was 29.6 \pm 0.6 , while among elderly suffering from OSA was $29.4 \pm 0.8^{5}$. The calculated sample size was 95 subjects and we could add $5.0 \%$ for a better quality of collected data so; the field sample was 100 patients.

\section{Tool of data collection:-}

Three tools were used for data collection:

Tool 1: Demographic and clinical data structured interview sheet

It consists of three parts:

Part I: Demographic characteristics of the geriatric patients with obstructive sleep apnea which include age, sex, 
marital status, residence, level of education, and occupation.

Part II: Medical history of geriatric patients with obstructive sleep apnea such as family history, symptoms of the disease, medical diseases, and medication used.

Part III: Clinical data related to disease including body weight, height, body mass index (BMI), Neck circumference, polysomnography data, and obstructive sleep apnea severity.

Tool 2: Epworth sleepiness scale (ESS) The Epworth Sleepiness Scale was developed by Johns (1991) ${ }^{6}$. It is a valid instrument used to measure excessive daytime sleepiness. It was translated into Arabic and was approved for validity and reliability by Ahmed et al (2014) ${ }^{7}$. The subject self-rates on how likely it is that he/she would doze in 8 different situations. The scoring of the answers is ranged from $0-3$, with 0 being "Would never doze" and 3 being "high chance of dozing" The total score ranged from 0 to 24 points. A score higher than 10 is usually used to denotes excessive daytime sleepiness.

Tool 3: Hospital Anxiety and
Depression Scale (HADS)
It was developed by Zigmond and Snaith (1983) ${ }^{8}$. HADS is used to assessing levels of anxiety and depression. It was translated into Arabic and was approved for validity and reliability by Abd El-Hamid (2010) ${ }^{9}$. HADS includes statements based on past week experience that the patient rates. The 14 statements involve common anxiety (seven statements) or 'depression' (seven statements), the final being mostly (but not entirely) consisting of reflections of the condition of anaerobia. There are 4 possible answers to each question. Answer choices varied between 3 and 0 . Both subscales, anxiety (HADS-
A) and depression (HADS-D) are independent measures. The total score of the scale range from $0-21$ point and patients can be categorized as the following: normal from $0-7$, mild from 8-10, moderate from 11-15, and severe from 16-21.

\section{Data collection process:}

1. An official letter was obtained from the Dean of Faculty of Nursing, Mansoura University to the responsible authorities to obtain their approval\& cooperation.

2. Tool I (Demographic and Clinical data structured interview schedule) was developed by the researcher based on relevant literature.

3. The Arabic version of tool II (Epworth Sleepiness Scale (ESS) was used by the researcher in this study. The reliability of this scale was assured by means of $r$ coefficient $(r=0.87)$.

4. The Arabic version of tool III (Hospital Anxiety and Depression Scale (HADS) was used by the researcher in this study. The reliability of this scale was assured by means of $r$ coefficient $(r=0.81)$.

5. Study tools (tool I, tool II, and tool III) were tested for content validity by a jury of five experts in the fields of Gerontological Nursing and Medical-Surgical Nursing. Accordingly, their recommended modifications had been done and the final forms were used for data collection.

6. A pilot study was conducted on $10 \%$ of the sample size of elderly patients from the same mentioned setting before starting data collection to check and confirm the applicability of the study tools. Based on the pilot study, necessary modification includes clarification, 
and rewording these elderly patients were excluded from the study sample and the results of the study.

7. After an explanation of the purpose of the study for each patient who fulfills the study criteria, and obtained a necessary verbal consent. Then, the necessary data were collected using the study tools.

8. According to the schedule of the outpatient clinic of the Chest Medicine Department at Main Mansoura University Hospital, The researcher visited the clinic 3 days per week. The time appropriated to complete the study tools lasted for 30 to 40 minutes.

9. Every geriatric patient was interviewed individually by the researcher to collect the necessary information via all study tools and reviewing patient's records.

10. The researcher started the interview by introducing herself to the eligible geriatric patient, giving a brief idea about the aim and nature of the study. Then the necessary data was taken.

11. Data collection started from the beginning of December 2019 till the end of March 2020.

\section{Ethical considerations:}

Ethical approval was obtained from Mansoura University, Faculty of Nursing Ethic Committee. Verbal consent was obtained from geriatric patients after explanation of the nature of the study. The participants were informed that their participation is voluntary and they can withdraw from the study at any time. Confidentiality and anonymity of the collected data were assured.

\section{Statistical analysis:}

The collected data were organized, tabulated and statistically analyzed using SPSS software (Statistical Package for the Social Sciences) version 22. For quantitative data, the range, mean and standard deviation were calculated. For qualitative data, which describe a categorical set of data by frequency, percentage or proportion of each category. ). For comparison between means of two groups of parametric data of independent samples, student t-test was used. For comparison between more than two means of parametric data, $F$ value of ANOVA test was calculated. Correlation between variables was evaluated using Pearson's correlation coefficient (r). Significance was adopted at $\mathrm{p}<0.05$ for interpretation of results of tests of significance. Regression to detect the most independent/ affecting factor for HAD scale was done.

\section{Results:}

Figure 1 shows that $47.0 \%$ of the studied patients had a moderate anxiety level, while $20.0 \%$ had a normal anxiety level. The total mean score of anxiety level was $12.03 \pm 3.76$ with a minimum of 5 and a maximum of 20 .

Figure 2 shows that $41.0 \%$ of the studied patients had mild depression levels and $23.0 \%$ had moderate depression levels. The total mean score of depression level was $9.16 \pm 2.86$ with a minimum of 2 and a maximum of 15 .

Figure 3 presented that $76.0 \%$ of the studied elder patients had excessive daytime sleepiness and only $24.0 \%$ had normal daytime sleepiness. The total mean score of daytime sleepiness was $15.14 \pm 5.86$.

Table 1 demonstrates the distribution of the studied elderly patients with obstructive sleep apnea according to their 
PSG findings. REM of the studied elderly patients ranged from 0.0 to 74.50 $\%$ from total sleep with a mean (REM) of $9.71 \pm 13.83$. The light sleep stage ranged from 25.50 to $100.0 \%$ with a mean light sleep of $86.42 \pm 12.53$ and the deep sleep stage $(\mathrm{N} 3)$ ranged from 0.0 to $28.70 \%$ with a mean deep sleep of 5.11 \pm 7. 30. Regarding the total sleep time (TST) of the studied elderly patients ranged from 2.0 to 6.0 hours with a mean (TST) of $4.87 \pm 1.08$.

As regards obstructive sleep apnea severity indicated by ApneaHypopnea Index (AHI), it was observed that $78.0 \%$ had severe obstructive sleep apnea, $14.0 \%$ had moderate obstructive sleep apnea and only $8.0 \%$ had mild obstructive sleep apnea. Moreover, the number of desaturation (NOD) ranged from 0.0 to 783.0 with a mean of 297.63 \pm 165.78 , and the sleep time with $\mathrm{O} 2$ saturation $<90 \%$ ranged from 0.0 to $100.0 \%$ with a mean of $39.06 \pm 32.52$, and the arousal index ranged from 16.0 to 736.0 events with a mean arousal index of $180.01 \pm 118.83$.

Table 2 shows that, the age of the studied elderly patients ranged from 60 to 82 years. Females constituted $61.0 \%$ of the studied patients. And $82.0 \%$ were married. Illiteracy was prevailing among $55.0 \%$ and only $12.0 \%$ of them had high education. Also, $55.0 \%$ were residing in rural areas and $68.0 \%$ were not working at current. Moreover, there is statistically significant relation was found between mean anxiety and depression level and older adults' educational level, as illiterate had greater anxiety and depression level than others $\left(\mathrm{p}=0.004^{*}\right.$ and $\mathrm{p}=0.001 *$ respectively). Also, there is statistical significant relation was found between mean anxiety level and geriatric patients' current work, as not working had greater anxiety level than others $\left(p=0.010^{*}\right)$. On the other hand, there is no statistically significant relation was found between mean anxiety and depression level and older adults' age, social status, and residence.

Table 3 shows that $65.0 \%$ of the studied elderly didn't use a denture, and 69.0\% of them were taking caffeine. Also, $73.0 \%$ of the study's elderly were not smoking. And 96.0\% were obese. Moreover, there is statistically significant relation was found between mean anxiety and depression level and older adults' using denture $\left(\mathrm{p}=0.001^{*}\right.$ and $\mathrm{p}=0.003^{*}$ respectively). On the other hand, no statistically significant relation was found between mean anxiety and depression level and taking caffeine, smoking, and body mass index (BMI).

Table 4 presents that there was a statistically positive significant correlation between daytime sleepiness, and anxiety level $\left(\mathrm{p}=0.001^{*}\right)$ indicating that obstructive sleep apnea patients with excessive daytime sleepiness had a higher level of anxiety. Also, there was a statistically positive significant correlation between anxiety level and depression level $(p<0.001 *)$ indicating that obstructive sleep apnea patients with higher anxiety had a higher level of depression. Moreover, the table shows that there was a statistically positive significant correlation between anxiety and depression level and OSA severity $(\mathrm{p}<0.001 *$ and $\mathrm{p}<0.001 *$ respectively) indicating that patients with severe obstructive sleep apnea had a higher level of anxiety and depression.

Table 5 shows the multivariate linear regression model for psychological health status. It was noticed from the table that OSA severity was a significant independent predictor for anxiety and depression $\left(\mathrm{p}<0.001^{*}\right)$ and responsible 
for $50 \%$ of anxiety and $40 \%$ of depression.

\section{Discussion}

Geriatric patients with obstructive sleep apnea can experience a deterioration of their mood, shown by symptoms of anxiety, and depression. The prevalence of depression varied from 7 to $63 \%$ and the prevalence of anxiety varied from 11 to $70 \%$ among patients ${ }^{10}$.

The present study showed that the majority of the studied elderly patients with OSA had anxiety. This result may be justified by OSA-related findings include bed partner symptoms, particularly loud snoring, breathing interruptions and frequent night awakens causing anxiety, and depression. This result is in accordance with a study done in Europa by Weaver et al., (2018) ${ }^{11}$ who reported increased symptoms of anxiety in the sleep disorder group with obstructive sleep apnea up to $50 \%$. Another study was done in Korea by Lee, Lee, Chung\& Kim, $(2015)^{12}$ who found High rates of anxiety are present in the sample of OSA patients. Moreover, the present study showed that more than half of the studied patients had depression. This finding is in accordance with a study done in Germany by Acker et al., (2016)13 who found high rates of depression present in OSA patients. Another study done in China by Cai, $\mathrm{Xu}$, Wei, Sun \& Chen, (2017) ${ }^{14}$ found that Seventy-four elderly patients were diagnosed with obstructive sleep apnea had depression disorders. In contrast, a study was done in Spain by Rey de Castro \& Rosales-Mayor, (2013) $)^{15}$ reported that a high percentage of the patients included in the study had minimum or nonexistent depression and anxiety symptoms.
Concerning daytime sleepiness, the present study pointed that most of the studied patients had higher daytime sleepiness. This result may be justified as; EDS is a common complaint in patients with OSA. This result agrees with a study done in Turkey by Balcan $\&$ Ozsancak Ugurlu, (2017) ${ }^{16}$ and In Italy by Angelelli et al., (2020) ${ }^{17}$ who found that most of the studied elders were sleepy. In contrast, a study was done in France by Sforza, Pichot, Martin, Barthelemy \& Roche, $(2016)^{18}$ reported that only $15 \%$ of the patients had excessive daytime sleepiness.

The majority of the studied patients in the present study had severe obstructive sleep apnea. This result may be justified as; the increase in Apnea Hypopnea Index with aging may be related to the increase in weight and the total number of respiratory arousals was significantly decreased in the elderly with OSA. The result of this study is in agreement with a study done in Japan by Hongyo et al, (2016) ${ }^{19}$ and in Brazil by Zhao, Viana, Ma \& Capasso, (2018) ${ }^{20}$ who found that the severity of OSA in elderly patients increased with aging.

The present study showed that OSA was encountered more among elderly women than men. This result may be related to loss of the protective effects of female reproductive hormones after menopause. This result agrees with study done in Italy by Silvestri et al., (2019) ${ }^{\mathbf{2 1}}$. In contrast, a study was done in USA by Heinzer et al., $(2015)^{22}$ reported that the prevalence of OSA is higher in elderly men than women.

Regarding the age of the studied geriatric patients, it was observed that age is the most important risk factor for developing OSA. This result agrees with a study done in Italy by Sunwoo et al., $(2018)^{23}$. Also, a study done in Egypt by 
Abbas, Zayed \& Awad, $(2020)^{24}$ reported that OSA is more common with increasing age.

Anxiety and depression of geriatric patients with OSA may depend on several factors in terms of demographic characteristics. The present study pointed that; illiterate elderly patients had more anxiety and depression symptoms. This result is supported by a study was done in Spain by Lee, Han \& Ryu, (2015) ${ }^{25}$. Another study done in Korea by Freeman et al., (2016) ${ }^{26}$ reported that lower education was associated with an increased risk of depression at follow-up. Also, the current study demonstrated that anxiety and depression were more prevalent in females than in males but there is no statistically significant relation was found between anxiety and depression score and older adults' sex. This result is the same of a study done in Australia by Edwards et al., (2015) ${ }^{27}$.

Depression and anxiety were more prevalent in obese older adults with OSA but there is no statistically significant relation was found between depression and anxiety scores with older adults' BMI in the current study. This result is in agreement with a study done in Iran by Razaeitalab et al., (2014) ${ }^{28}$. In contrast, in a study done in Pennsylvania by Björnsdóttir et al., $(2016)^{29}$, found that there is a statistically significant relation was found between anxiety and depression scores and older adults' BMI.

The present study showed a statistically positive significant correlation between daytime sleepiness and anxiety level. The same result were reported in a study Korea by Lee, Han \& Ryu, (2015) ${ }^{25}$, and a study done in turkey by Yazici \& Hatipoglu, (2019) ${ }^{30}$. Moreover, the present study findings showed that there was a statistically positive significant correlation between daytime sleepiness and obstructive sleep apnea severity. This result is supported by a study done in Poland by Gabryelska \& Białasiewicz, $(2020)^{31}$.

A statistically positive significant correlation between anxiety and depression scores and AHI was found in the current study. This result is supported by a study done in Greece by Diamanti et al., $(2013)^{32}$. Also, another study was done in China by Dai et al., $(2016)^{33}$ found that there was a statistically positive significant correlation between depression scores and AHI.

In the multivariate linear regression model, the current study approved that obstructive sleep apnea severity (AHI) was a significant independent predictor for anxiety and depression. This result is supported by a study done in Australia by Edwards et al., $(2015)^{28}$ and another study was done in Netherlands by Luik., et al (2015) ${ }^{34}$.

\section{Conclusion}

Based on the results of the present study, it can be concluded that psychological symptoms include anxiety and depression are common among geriatric patients with obstructive sleep apnea. Also, a statistically significant correlation was found between psychological health status and daytime sleepiness as well as OSA severity. Moreover, Obstructive sleep apnea severity was proved to be a significant independent predictor for anxiety and depression.

\section{Recommendations}

1- Designing an educational program for obstructive sleep apnea geriatric patients about treatment adherence to improve their psychological health status.

2- Implementation of an intervention program for nursing staff about 


$\begin{array}{ll}\text { problems faced in caring for } & \text { We would like to thank all health } \\ \text { patients with obstructive sleep } & \text { personnel in the outpatient clinic of the } \\ \text { apnea to help them to provide } & \text { Chest Medicine Department at Main } \\ \text { optimal care and early screening of } & \text { Mansoura University Hospital, Egypt as } \\ \text { psychological problems. } & \text { well as geriatric patients for their } \\ \text { Acknowledgment } & \text { participation to fulfill this study. }\end{array}$

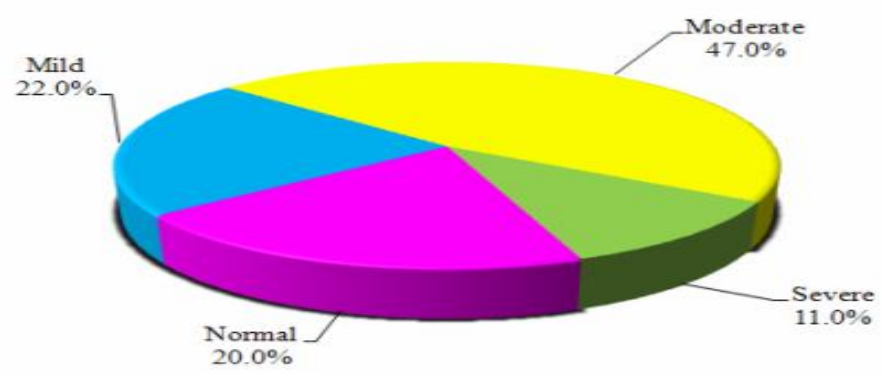

Figure 1: Distribution of the studied geriatric patients with obstructive sleep apnea according to anxiety.

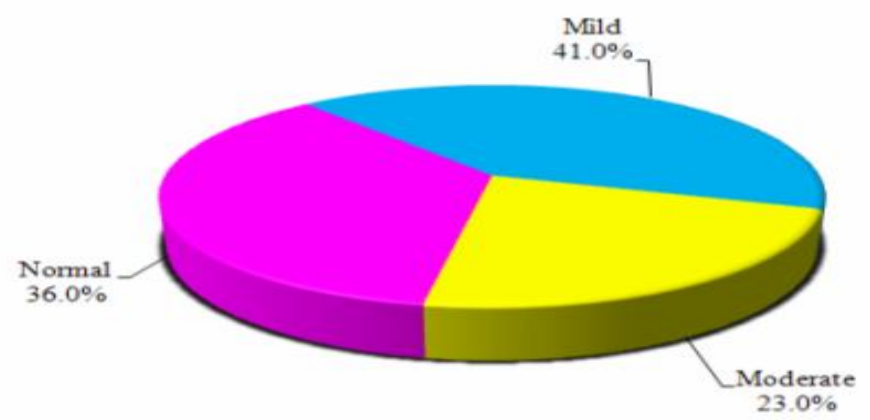

Figure 2: Distribution of the studied geriatric patients with obstructive sleep apnea according to depression.

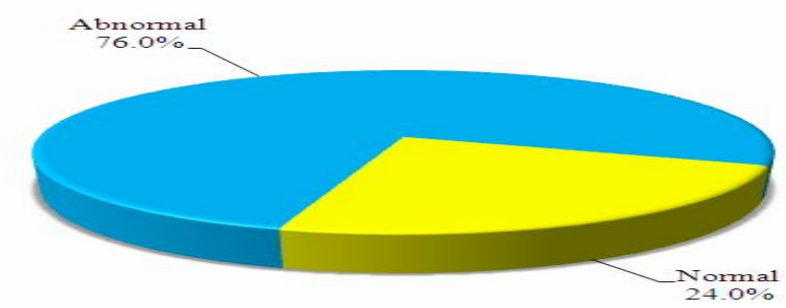

Figure 3: Distribution of the studied geriatric patients with obstructive sleep apnea according to daytime sleepiness. 
Assessment of Psychological Health Status in Geriatric etc...

Table1:Distribution of the studied geriatric patients with obstructive sleep apnea according to their Polysomnography data $(n=100)$

\begin{tabular}{|l|c|c|}
\hline Patient's Polysomnography Data & Min. - Max. & Mean \pm SD. \\
\hline Sleep stages & & \\
\hline Rabid eye movement (REM) (\%) & $0.0-74.50$ & $9.71 \pm 13.83$ \\
\hline Light sleep (\%) & $25.50-100.0$ & $86.42 \pm 12.53$ \\
\hline Deep sleep (\%) & $0.0-28.70$ & $5.11 \pm 7.30$ \\
\hline Sleep measures & & \\
\hline Total sleep time (hours) & $2.0-6.0$ & $4.87 \pm 1.08$ \\
\hline Apnea hypopnea index (AHI) & No. & \% \\
\hline Mild (AHI $\geq 5 \leq 15)$ & 8 & 8.0 \\
\hline Moderate (AHI $>15 \leq 30)$ & 14 & 14.0 \\
\hline Sever (AHI $>30)$ & 78 & 78.0 \\
\hline Apnea hypopnea index (AHI) & $5.0-179.80$ & $56.54 \pm 29.93$ \\
\hline O2 saturation & & \\
\hline Number of desaturation (NOD) & $0.0-783.0$ & $297.63 \pm 165.78$ \\
\hline Sleep time with 02 saturation $<90 \%$ & $0.0-100.0$ & $39.06 \pm 32.52$ \\
\hline Arousal index & $16.0-736.0$ & $180.01 \pm 118.83$ \\
\hline
\end{tabular}

Table 2: Relationship between demographic characteristics, and psychological health status of the studied geriatric patients with obstructive sleep apnea

\begin{tabular}{|c|c|c|c|}
\hline \multirow[b]{2}{*}{ Items } & \multirow[b]{2}{*}{$\mathrm{N}=100$} & \multicolumn{2}{|c|}{ Psychological Health Status } \\
\hline & & $\begin{array}{c}\text { Anxiety } \\
\text { Mean } \pm \text { SD }\end{array}$ & $\begin{array}{c}\text { Depression } \\
\text { Mean } \pm \text { SD }\end{array}$ \\
\hline $\begin{array}{l}\text { Age } \\
60- \\
65- \\
70 \\
\text { More than } 75\end{array}$ & $\begin{array}{l}57 \\
21 \\
17 \\
5\end{array}$ & $\begin{array}{l}11.53 \pm 3.60 \\
12.10 \pm 4.43 \\
12.88 \pm 3.72 \\
14.60 \pm 0.55\end{array}$ & $\begin{array}{c}8.88 \pm 2.78 \\
9.05 \pm 2.87 \\
9.71 \pm 3.24 \\
11.00 \pm 2.00\end{array}$ \\
\hline $\mathbf{F}(\mathbf{p})$ & & $1.430(0.239)$ & $1.099(0.353)$ \\
\hline $\begin{array}{l}\text { Sex } \\
\text { Female } \\
\text { Male } \\
\end{array}$ & $\begin{array}{l}61 \\
39 \\
\end{array}$ & $\begin{array}{l}12.41 \pm 3.91 \\
11.44 \pm 3.48\end{array}$ & $\begin{array}{l}9.31 \pm 2.79 \\
8.92 \pm 2.98 \\
\end{array}$ \\
\hline$t(p)$ & & $0.521(0.596)$ & $0.696(0.501)$ \\
\hline $\begin{array}{l}\text { social status } \\
\text { Married } \\
\text { Widow } \\
\text { Divorced }\end{array}$ & $\begin{array}{c}82 \\
12 \\
6\end{array}$ & $\begin{array}{l}11.94 \pm 3.73 \\
13.00 \pm 4.24 \\
11.33 \pm 3.44\end{array}$ & $\begin{array}{l}9.13 \pm 2.91 \\
9.83 \pm 2.92 \\
8.17 \pm 1.72\end{array}$ \\
\hline$F(p)$ & & $0.521(0.596)$ & $0.696(0.501)$ \\
\hline $\begin{array}{l}\text { Educational level } \\
\text { Illiterate } \\
\text { Read and write } \\
\text { High education }\end{array}$ & $\begin{array}{l}55 \\
33 \\
12\end{array}$ & $\begin{array}{c}13.05 \pm 3.26 \\
11.18 \pm 4.16 \\
9.67 \pm 3.34\end{array}$ & $\begin{array}{l}9.95 \pm 2.56 \\
8.70 \pm 2.95 \\
6.83 \pm 2.52\end{array}$ \\
\hline $\mathbf{F}(\mathbf{p})$ & & $5.751^{*}\left(0.004^{*}\right)$ & $7.327^{*}\left(0.001^{*}\right)$ \\
\hline $\begin{array}{l}\text { Residence } \\
\text { Rural } \\
\text { Urban }\end{array}$ & $\begin{array}{l}55 \\
45\end{array}$ & $\begin{array}{l}12.55 \pm 3.77 \\
11.40 \pm 3.70\end{array}$ & $\begin{array}{l}9.16 \pm 2.54 \\
9.16 \pm 3.23\end{array}$ \\
\hline $\mathbf{t}(\mathbf{p})$ & & $1.525(0.130)$ & $0.014(0.989)$ \\
\hline $\begin{array}{l}\text { Current work } \\
\text { No } \\
\text { Yes }\end{array}$ & $\begin{array}{l}68 \\
32\end{array}$ & $\begin{array}{l}12.69 \pm 3.73 \\
10.63 \pm 3.49\end{array}$ & $\begin{array}{l}9.49 \pm 2.79 \\
8.47 \pm 2.91\end{array}$ \\
\hline$t(p)$ & & $2.638 *(0.010 *)$ & $1.676(0.097)$ \\
\hline
\end{tabular}


Hanem Reda Bassuni Anan1et. al

Table3:Relationship between health-related history, and psychological health of the studied geriatric patients with obstructive sleep apnea

\begin{tabular}{|c|c|c|c|}
\hline \multirow[b]{2}{*}{ Items } & \multirow{2}{*}{$\mathrm{N}=100$} & \multicolumn{2}{|c|}{$\begin{array}{l}\text { Psychological Health Status } \\
\end{array}$} \\
\hline & & $\begin{array}{c}\text { Anxiety } \\
\text { Mean } \pm \text { SD }\end{array}$ & $\begin{array}{l}\text { Depression } \\
\text { Mean } \pm \text { SD }\end{array}$ \\
\hline \multicolumn{4}{|l|}{ Using a denture } \\
\hline No & 65 & $11.15 \pm 3.76$ & $8.55 \pm 2.73$ \\
\hline Yes & 35 & $13.66 \pm 3.23$ & $10.29 \pm 2.77$ \\
\hline$t(p)$ & & $3.489 *(0.001 *)$ & $3.008 *(0.003 *)$ \\
\hline \multicolumn{4}{|l|}{ Taking caffeine } \\
\hline Yes & 69 & $22.30 \pm 4.17$ & $11.84 \pm 3.80$ \\
\hline No & 31 & $22.29 \pm 2.81$ & $12.45 \pm 3.70$ \\
\hline$t(p)$ & & $0.750(0.455)$ & $0.255(0.799)$ \\
\hline \multicolumn{4}{|l|}{ Smoking } \\
\hline No & 73 & $12.37 \pm 3.78$ & $9.37 \pm 2.79$ \\
\hline Yes & 27 & $11.11 \pm 3.61$ & $8.59 \pm 3.02$ \\
\hline$t(p)$ & & $1.495(0.138)$ & $1.211(0.229)$ \\
\hline \multicolumn{4}{|l|}{ BM I (Kg/m) } \\
\hline Obese $(\geq 30)$ & 96 & $12.13 \pm 3.73$ & $9.19 \pm 2.84$ \\
\hline Over weight (25-29.99) & 3 & $11.00 \pm 4.58$ & $9.00 \pm 4.36$ \\
\hline Normal weight(18.5- 24.99) & 1 & 6.0 & 7.0 \\
\hline $\mathrm{F}(\mathrm{p})$ & & $1.441(0.242)$ & $0.291(0.748)$ \\
\hline
\end{tabular}

$\mathrm{T}$ : Student t-test

$\mathrm{F}(\mathrm{p})$

$\mathrm{P}: \mathrm{p}$-value for the association between different categories

*: Statistically significant at $\mathrm{p} \leq 0.05$

Table 4: Correlation between day time sleepiness, psychological health status, and OSA severity

\begin{tabular}{|l|c|c|c|c|}
\hline \multirow{2}{*}{ Items } & & \multicolumn{2}{|c|}{ Psychological health status } & \multirow{2}{*}{ OSA severity } \\
\cline { 3 - 4 } & & Anxiety & Depression & \\
\hline \multirow{2}{*}{ Day time sleepiness } & $\mathbf{R}$ & $\mathbf{0 . 3 3 2}$ & $\mathbf{0 . 1 7 5}$ & $\mathbf{0 . 2 5 6 ^ { * }}$ \\
\cline { 2 - 5 } & $\mathbf{P}$ & $\mathbf{0 . 0 0 1 *}$ & $\mathbf{0 . 0 8 2}$ & $\mathbf{0 . 0 1 0 ^ { * }}$ \\
\hline \multirow{2}{*}{ Anxiety } & $\mathbf{R}$ & & $\mathbf{0 . 8 0 0 *}$ & $\mathbf{0 . 6 9 5 ^ { * }}$ \\
\cline { 2 - 5 } & $\mathbf{P}$ & & $<\mathbf{0 . 0 0 1 *}$ & $<\mathbf{0 . 0 0 1 ^ { * }}$ \\
\hline \multirow{2}{*}{ Depression } & $\mathbf{R}$ & & & $\mathbf{0 . 6 3 2 *}$ \\
\cline { 2 - 5 } & $\mathbf{P}$ & & & $<\mathbf{0 . 0 0 1 *}$ \\
\hline
\end{tabular}

R: Pearson coefficient

*: Statistically significant at $\mathrm{p} \leq 0.05$

OSA: obstructive sleep apnea

Table 5: Multivariate Linear regression model for the psychological health status

\begin{tabular}{|l|c|c|c|c|}
\hline \multicolumn{1}{|c|}{ Anxiety } & B & Beta & T & P \\
\hline Day time sleepiness & 0.106 & 0.165 & $2.238^{*}$ & $0.028^{*}$ \\
\hline Obstructive sleep apnea severity (AHI) & 0.082 & 0.009 & $8.860^{*}$ & $<0.001^{*}$ \\
\hline \multicolumn{3}{|c|}{$\mathrm{R} 2=0.511, \mathrm{~F}=50.710^{*}, \mathrm{p}<0.001$} \\
\hline Depression & & & & \\
\hline Day time sleepiness & 0.007 & 0.014 & 0.169 & 0.866 \\
\hline Obstructive sleep apnea severity (AHI) & 0.060 & 0.629 & $7.726^{*}$ & $<0.001^{*}$ \\
\hline Day time sleepiness & 0.007 & 0.014 & 0.169 & 0.866 \\
\hline $\mathrm{R} 2=0.508, \mathrm{~F}=50.131^{*}, \mathrm{p}<0.001^{*}$ \\
\hline
\end{tabular}

F,p: $f$, and $p$ values for the model R2: Coefficient of determination 


\begin{tabular}{ll}
\hline \hline Beta: Standardized Coefficients & B: Unstandardized Coefficients \\
t: t-test of significance & $*$ : Statistically significant at $\mathrm{p} \leq 0.05$
\end{tabular}

\section{References}

[1] Zeineddine, S., \& Chowdhuri, S. (2019). Apnea in Elderly. Current Sleep Medicine Reports, 5(1), 1322.https://doi.org/10.1007/s40675019-0134-y.

[2] Barewal, R. (2019). Obstructive Sleep Apnea. Dental Clinics of North America, 63(2), 297-308. doi: 10.1016/j.cden.2018.11.009.

[3] Babazadeh, T., Sarkhoshi, R., Bahadori, F., Moradi, F., Shariat, F., \& Sherizadeh, Y. U. S. E. F. (2016). Prevalence of depression, anxiety, and stress disorders in elderly people residing in Khoy, Iran (2014-2015). Journal of Analytical Research in Clinical Medicine, 4(2), 122-128. https://doi.org/10.15171/jarcm.201 6.020

[4] Jackson, M., Muruganandan, S., Churchward, T., Tolson, J., \& Worsnop, C. (2019). Crosssectional examination of gender differences in depression and anxiety symptoms in patients with obstructive sleep apnea. Sleep and Biological Rhythms, 17(4), 455458. doi: 10.1007/s41105-01900225-0

[5] Torelli, F., Moscufo, N., Garreffa, G., Placidi, F., Romigi, A., Zannino, S., ... \& Malhotra, A. (2011). Cognitive profile and brain morphological changes in obstructive sleep apnea. Neuroimage, 54(2), 787-793.

[6] Johns, M. W. (1991). A new method for measuring daytime sleepiness: the Epworth sleepiness scale. Sleep, 14(6), 540-545.

[7] Ahmed, A. E., Fatani, A., AlHarbi, A., Al-Shimemeri, A., Ali,
Y. Z., Baharoon, S., \& Al-Jahdali, H. (2014). Validation of the Arabic version of the Epworth Sleepiness Scale. Journal of Epidemiology and Global Health, 4(4), 297-

[8] Zigmond, A. S., \& Snaith, R. P. (1983). The hospital anxiety and depression scale. Actapsychiatric Ascandinavica, 67(6), 361-370.

[9] Abd El-Hamid SH (2010). Caregivers training and health status outcomes in cerebral stroke elder patients. Published Doctoral Thesis. Faculty of Nursing. Alexandria University.

[10] Bahammam, A., Kendzerska, T., Gupta, R., Ramasubramanian, C., Neubauer, D., \& Narasimhan, M. et al. (2016). Comorbid depression in obstructive sleep apnea: an under-recognized association. Sleep and Breathing, 20(2), 447456. tps://doi.org/10.1007/s11325015-1223-x

[11]Weaver, M., Vetter, C., Rajaratnam, S., O'Brien, C., Qadri, S., \& Benca, R. et al. (2018). Sleep disorders, depression and anxiety are associated with adverse safety outcomes in healthcare workers: A prospective cohort study. Journal of Sleep Research, 27(6), e12722. doi: $10.1111 /$ jsr.12722.

[12] Lee, S. A., Lee, S. A., Chung, Y. S., \& Kim, W. S. (2015b). The relation between apnea and depressive symptoms in men with severe obstructive sleep apnea: Meditational effects of sleep quality. Lung, 193(2), 261-267. doi:10.1007/s00408-015-9687-9 
[13] Acker, J., Richter, K., Piehl, A., Herold, J., Ficker, J., \& Niklewski, G. (2016). Obstructive sleep apnea (OSA) and clinical depressionprevalence in a sleep center. Sleep and Breathing, 21(2), 311-318. doi: 10.1007/s11325-016-1411-3

[14] Cai, L., Xu, L., Wei, L., Sun, Y., \& Chen, W. (2017). Evaluation of the risk factors of depressive disorders comorbid with obstructive sleep apnea. Neuropsychiatric Disease and Treatment, Volume 13, 155-159. doi: $10.2147 /$ ndt.s122615

[15] Rey de Castro, J., \& RosalesMayor, E. (2013). Depressive symptoms in patients with obstructive sleep apnea/hypopnea syndrome. Sleep and Breathing, 17(2), 615-620. doi: 10.1007/s11325-012-0731-1

[18] Balcan, B., \& Ozsancak Ugurlu, A. (2017). Results of Polysomnographies and Treatment Strategies in Elderly Patients with Symptoms of Obstructive Sleep Apnea Syndrome. Turkish Thoracic Journal, 18(4), 108-113. doi: .5152/turkthoracj.2017.17019

[19] Angelelli, P., Macchitella, L., Toraldo, D., Abbate, E., Marinelli, C., Arigliani, M., \& De Benedetto, M. (2020). The Neuropsychological Profile of Attention Deficits of Patients with Obstructive Sleep Apnea: An Update on the Daytime Attentional Impairment. Brain Sciences, 10(6), 325. doi: 10.3390/brainsci10060325

[20] Sforza, E., Saint Martin, M., Barthélémy, J., \& Roche, F. (2016). Mood disorders in healthy elderly with obstructive sleep apnea: a gender effect. Sleep
Medicine, 19, 57-62. doi: 10.1016/j.sleep.2015.11.007

[19] Hongyo, K., Ito, N., Yamamoto, K., Yasunobe, Y., Takeda, M., \& Oguro, R. et al. (2016). Factors associated with the severity of obstructive sleep apnea in older adults. Geriatrics \& Gerontology International, 17(4), 614-621. doi: 10.1111/ggi.12768

[20] Zhao, C., Viana, A., Ma, Y., \& Capasso, R. (2018). The effect of aging on drug-induced sleep endoscopy findings. The Laryngoscope, 128(11), 26442650. doi: 10.1002/lary. 27265

[21] Silvestri, R., Aricò, I., Bonanni, E., Bonsignore, M., Caretto, M., \& Caruso, D. et al. (2019). Italian Association of Sleep Medicine (AIMS) position statement and guideline on the treatment of menopausal sleep disorders. Maturitas, 129, 30-39. doi: 10.1016/j.maturitas.2019.08.006

[22] Heinzer, R., Marti-Soler, H., \& Haba-Rubio, J. (2016). Prevalence of sleep apnoea syndrome in the middle to old age general population. The Lancet Respiratory Medicine, 4(2), e5-e6. doi:10.1016/s2213-600(16)00006-

[23] Sunwoo, J., Hwangbo, Y., Kim, W., Chu, M., Yun, C., \& Yang, K. (2018). Prevalence, sleep characteristics, and comorbidities in a population at high risk for obstructive sleep apnea: A nationwide questionnaire study in South Korea. PLOS ONE, 13(2), $\mathrm{e} 0193549$. doi: 10.1371/journal.pone.0193549

[24] Abbas, A., Zayed, N., \& Awad, M. (2020). Predictors of atrial fibrillation among patients with obstructive sleep apnea. The 
Egyptian Journal of Chest Diseases and Tuberculosis, 69(3), 57doi: 10.4103/ejcdt.ejcdt_194_19

[25] Lee, S., Han, S., \& $\bar{R} y u,-H$. (2015). Anxiety and its relationship to quality of life independent of depression in patients with obstructive sleep apnea. Journal Of Psychosomatic Research, 79(1), 32-36. doi: 10.1016/j.jpsychores.2015.01.012

[26] Freeman, A., Tyrovolas, S., Koyanagi, A., Chatterji, S., Leonardi, M., \& Ayuso-Mateos, J. et al. (2016). The role of socioeconomic status in depression: results from the COURAGE (aging survey in Europe). BMC Public Health, 16(1). doi: 10.1186/s12889-016-3638-0

[27] Edwards, C., Mukherjee, S., Simpson, L., Palmer, L., Almeida, O., \& Hillman, D. (2015). Depressive Symptoms before and after Treatment of Obstructive Sleep Apnea in Men and Women. Journal Of Clinical Sleep Medicine, 11(09), 1029-1038. doi: $10.5664 / \mathrm{jcsm} .5020$.

[28] Rezaeitalab, F., Moharrari, F., Saberi, S., Asadpour, H., \& Rezaeetalab, F. (2014). The correlation of anxiety and depression with obstructive sleep apnea syndrome. Journal of research in medical sciences: the official journal of Isfahan University of Medical Sciences, 19(3), 205.

[29] Björnsdóttir, E., Benediktsdóttir, B., Pack, A. I., Arnardottir, E. S., Kuna, S. T., Gíslason, T., ... Sigurdsson, J. F. (2016). The prevalence of depression among untreated obstructive sleep apnea patients using a standardized psychiatric interview. Journal of Clinical Sleep Medicine, 12(1), 105-112. doi:10.5664/jcsm.5406

[30] Yazici, O., \& Hatipoglu, O. (2019). Evaluation of quality of life, anxiety, and depression in the spouses of patients with obstructive sleep apnea syndrome. Nigerian Journal Of Clinical Practice, 22(4), 516. doi: $10.4103 /$ njcp.njcp_500_18

[31] Gabryelska, A., \& Białasiewicz, P. (2020). Association between excessive daytime sleepiness, REM phenotype and severity of obstructive sleep apnea. Scientific Reports, 10(1). doi: 10.1038/s41598-019-56478-9

[32] Diamanti, C., Manali, E., GinieriCoccosis, M., Vougas, K., Cholidou, K., Markozannes, E., ... Alchanatis, M. (2013).Depression, physical activity, energy consumption, and quality of life in OSA patients before and after CPAP treatment. Sleep \& Breathing, 17(4), 1159-1168. doi:10.1007/s11325-013-0815-6

[33] Dai, Y., Li, X., Zhang, X., Wang, S., Sang, J., Tian, X., \& Cao, H. (2016). Prevalence and Predisposing Factors for Depressive Status in Chinese Patients with Obstructive Sleep Apnoea: A Large-Sample Survey. PLOS ONE, 11(3), e0149939. doi: 10.1371/journal.pone.0149939.

[34] Luik, A. I., Noteboom, J., Zuurbier, L. A., Whitmore, H., Hofman, A., \& Tiemeier, $\mathrm{H}$. (2015). Sleep apnea severity and depressive symptoms in a population-based study. Sleep Health, 1(128-132 